\title{
Conservative treatment of chronic Achilles tendinopathy
}

\author{
Alex Scott RPT PhD, Elise Huisman MSc, Karim Khan MD PhD
}

A chilles tendinopathy is a common condition, particularly in those who run. It is a chronic, activity-limiting syndrome, defined by the presence of pain and thickening in the Achilles tendon (Figure $1^{1}$ ). The lifetime prevalence of Achilles tendinopathy is 52\% in former runners, and the annual incidence is $7 \%$ $9 \%$ in current runners. ${ }^{2}$ This syndrome encompasses several overlapping pathologies and is clinically distinct from rupture or partial rupture. Onset is typically insidious and chronic in nature, although occasionally a patient may present with acute tendinopathy.

A classification system for disorders of the Achilles tendon is presented in Table 1,3 based on physical examination, imaging and histopathology. However, there is no widely accepted schema. There has been a largely successful movement to abandon use of the term "tendinitis" for patients with symptoms that last longer than three months, in recognition of the need to address degenerative structural changes within the tendon (i.e., tendinosis) rather than inflammation, which is rarely or only minimally present in most instances. ${ }^{5}$ It is often not possible to distinguish tendinosis from paratendonitis (i.e., inflammation around the tendon) and these frequently coexist, which is another argument in favour of the more general term, "tendinopathy." Nonetheless, an attempt to diagnose the source of pain (tendon v. paratendon) should be made.

The high prevalence among runners points to mechanical loading as an important etiologic factor. ${ }^{2}$ In vitro and in vivo research suggests that periods of mechanical overuse result in subclinical evidence of inflammatory or pseudoinflammatory change. 6 The term "pseudo" is used to recognize that full-blown cellular inflammation may not be present in an overloaded tendon; however, tenocytes themselves can produce certain inflammatory mediators in response to increased loading, such as substance $\mathrm{P}$ and prostaglandin E2. Over time, these episodes may lead to cumulative changes in the tendon, eventually resulting in the development of tendinosis, paratendonitis or both. ${ }^{7,8}$

There is no universally accepted model of the development of injury from overuse of a tendon. ${ }^{9}$ A minority of patients with Achilles tendinopathy have sedentary lifestyles and no identifiable history of mechanical overload, which suggests that mechanical loading is not the only risk factor. ${ }^{2}$ Indeed, multiple risk factors have been identified in small associational studies, including advancing age, male sex, high body mass index, hypercholesterolemia and the presence of genetic variants of genes related to collagen metabolism. ${ }^{10,11}$

The diagnosis can be made on the basis of history and physical examination (Appendix 1, available at www.cmaj.ca/lookup/suppl/doi:10.1503 /cmaj.101680/-/DC1). Colour Doppler ultrasonography or magnetic resonance imaging can be helpful in identifying the type of Achilles tendinopathy.

In this review, we discuss the evidence base for conservative management of chronic midportion Achilles tendinopathy. For a discussion of surgical techniques, please see other recent reviews (e.g., Maffulli and coauthors ${ }^{12}$ ). A plethora of conservative treatments have been suggested to provide relief from, or cures for, Achilles tendinopathy, including nonsteroidal anti-inflammatory drugs (NSAIDs), ultrasound and laser therapy, nutritional supplements, friction massage and dry needling. However, most are not supported by randomized controlled trials. Our objective was to review the evidence found in randomized controlled trials for conservative treatment of chronic (i.e., greater than three months' duration) midportion Achilles tendinopathy (Box $1^{13-23}$ ).

\section{Is exercise an effective treatment?}

The only intervention with strong evidence of a treatment effect in randomized controlled trials was heavy-load exercise. This form of exercise
Competing interests: None declared.

This article has been peer reviewed.

Correspondence to:

Dr. Alex Scott,

alex.scott@ubc.ca

CMAJ 2011. DOI:10.1503

/cmaj.101680

\section{- Ker poINTS}

- Heavy-load (eccentric) exercise is currently the cornerstone of management of chronic Achilles tendinopathy, but it may take up to 12 weeks or longer of daily supervised exercise to see substantial improvements.

- Nonsteroidal anti-inflammatory drugs have little long-term benefit and there is insufficient evidence to support use of shock wave therapy.

- Corticosteroid injections should be avoided and other injection therapies are still in the experimental stage.

- Orthotics may be helpful in patients with an identifiable biomechanical abnormality, but braces and splints have no proven benefit. 
varies slightly from trial to trial, but the principal goal is to provide a strong, controlled, mechanical force to the Achilles tendon. This is usually achieved through eccentric (lengthening) muscle activity; for instance, a heel drop over a step. (In contrast, concentric exercise would involve a toe raise that would contract the calf muscles.) As the patient's tolerance of the exercise improves, the load is progressively increased (e.g., by progressing from bilateral to unilateral heel drops, by adding weights in a backpack or through use of gym equipment). Rompe and colleagues found this type of progressive heavy-load exercise to be superior to a wait-and-see strategy, with a $60 \%$ success rate in the exercise group (95\% confidence interval [CI] 41\%-79\%) compared with $24 \%$ in controls who did not receive treatment $(95 \%$ CI $7 \%-41 \%) .{ }^{14}$

Eccentric exercise was found to be superior to a standard exercise program in a multicentre randomized trial by Mafi and colleagues; $82 \%$ of the patients who trained with eccentric exercise were satisfied and had returned to their previous activity level after 12 weeks (95\% CI 66\%-98\%), compared with $36 \%$ of patients who trained with standard (concentric) exercise (95\% CI 16\%-56\%). ${ }^{15}$ Thus, eccentric exercise induces clinically mean-

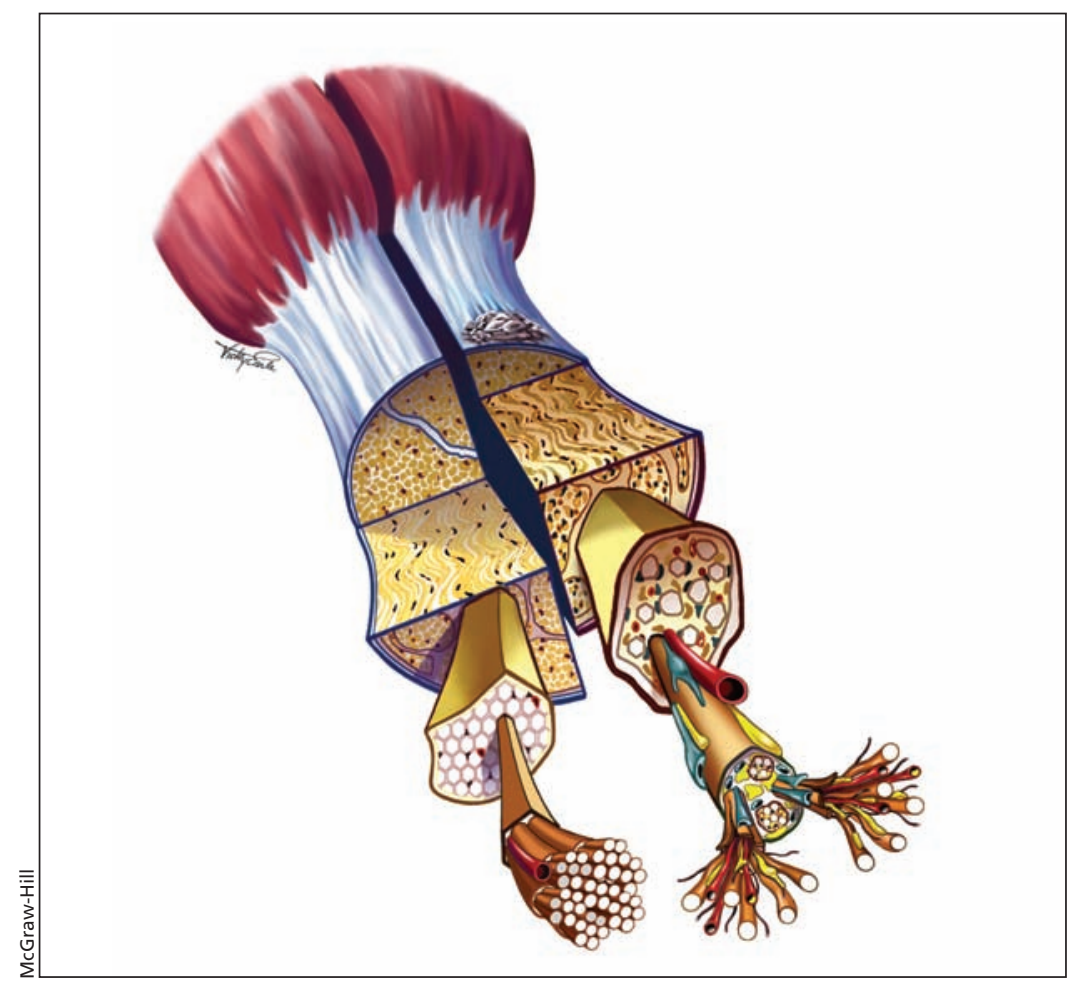

Figure 1: Schematic view of the Achilles tendon. Left: Normal tendon showing a white glistening appearance, with tightly bundled type I collagen fibres, sparse cellularity and minimal vascularity. Right: Tendinopathic tendon showing a yellowish or greyish appearance, with underlying findings of tendinosis, which may include smaller and more disorganized fibrils, increased cellularity and vascularity, and increased proteoglycan (blue) and lipid (yellow) accumulation. Reproduced with permission from Brukner and Khan. ${ }^{1}$ ingful effects but may take several weeks or months before a benefit is felt, and not every patient is guaranteed to respond. The exercise should be taught and monitored by a health professional, such as a physiotherapist or sports medicine physician, capable of ensuring correct biomechanics (e.g., avoiding pronation) and of supervising the gradual increase of tendon loading.

The potential harms of eccentric exercise include delayed-onset muscle soreness or exacerbation of the tendinopathy (e.g., pain, soreness or swelling). These typically occur when the exercises are performed too quickly, with incorrect biomechanics or with an increase in load that is too abrupt. There are no published reports of tendon rupture in response to eccentric loading.

\section{Do orthotics, braces or splints have a positive effect?}

Orthotics may be helpful in conjunction with other modalities of treatment if there is an identifiable malalignment, whereas braces or splints do not appear to improve outcomes in Achilles tendinopathy. One randomized controlled trial of male runners found a significant improvement in pain in patients wearing custom-made orthotics. ${ }^{17}$ Of the patients, $89 \%$ described a reduction in pain scores of greater than $50 \%$ after four weeks of wearing custom insoles (95\% CI 69\%-100\%), compared with $0 \%$ in control patients who did not receive treatment $(p<0.05)$. This trial may have had improper blinding, because sham insoles were not provided to the control group. Referral to a qualified orthotist should be considered if the biomechanical examination identifies a potentially correctable malalignment. However, there is little evidence to suggest that orthotics alone will be effective.

An inflatable brace was examined in two separate studies. The brace is commercially available (AirHeel [Aircast]) and designed to be worn during activity. An earlier study by Petersen and coworkers could not detect differences between groups and recommended further study. ${ }^{20}$ In a subsequent larger study, Knobloch and colleagues randomly assigned 116 patients to undergo treatment consisting of eccentric training or eccentric training plus prescription of an AirHeel brace. Both groups achieved similar improvements in pain after 12 weeks, which showed that the addition of the AirHeel brace did not improve the success of rehabilitation. ${ }^{19}$

Other authors have advocated use of a night splint, as commonly prescribed for patients with plantar fasciitis. de Vos and colleagues randomly assigned patients to complete a heavy-load 
eccentric training program with or without use of a night splint. After 12 weeks, $63 \%$ of patients in the group that received only exercise were satisfied (95\% CI 47\%-79\%), compared with $48 \%$ in the night splint group (95\% CI 32\%-64\%), and there were no significant differences in pain or other outcome measures. ${ }^{21}$

\section{What is the role of physiotherapy?}

Many clinicians recognize that an individualized physiotherapy program that addresses the patient's specific presentation, loading history and biomechanics leads to the most effective outcomes when combined with exercise. However, published evidence for these complex interventions is still lacking, particularly for longer-term outcomes.

One trial examined the short-term effect of physiotherapy, including ice, transverse friction massage, therapeutic ultrasound and exercise (i.e., concentric, eccentric, balance and proprio- ceptive drills), compared with control (no treatment). ${ }^{17}$ The physiotherapy group $(n=11)$ experienced significant improvements in activityrelated pain compared with controls $(n=8)(p<$ 0.05 ). Effect size could not be calculated, which made a comparison with other trials that used exercise alone impossible. The trial included only men and used a multimodal intervention that closely approximates interventions currently provided by many sports medicine physiotherapy clinics, rather than exercise alone.

\section{Which other modalities may be helpful?}

Many modalities have been used in the treatment of chronic Achilles tendinopathy. Some that are used frequently, such as NSAIDS, have little long-term benefit, whereas current evidence for less commonly used options, such as extracorporeal shock wave therapy and glyceryl

Table 1: Classification of disorders of the Achilles tendon, with typical findings $s^{3,4}$

\begin{tabular}{|c|c|c|c|c|}
\hline Pathologic diagnosis & $\begin{array}{c}\text { Concept (macroscopic } \\
\text { pathology) }\end{array}$ & Physical examination & Imaging & Histopathology \\
\hline Tendinosis* & $\begin{array}{l}\text { Intratendinous } \\
\text { degeneration }\end{array}$ & $\begin{array}{l}\text { Tendon thickening and } \\
\text { tenderness on palpation } \\
\text { of the midportion }\end{array}$ & $\begin{array}{l}\text { Hypoechoic areas on } \\
\text { grey-scale } \\
\text { ultrasonography; } \\
\text { increased tendon } \\
\text { thickness; increased } \\
\text { colour Doppler signal, } \\
\text { usually originating } \\
\text { from deep surface }\end{array}$ & $\begin{array}{l}\text { Collagen disorientation, } \\
\text { disorganization and fibre } \\
\text { separation; hypervascularity; } \\
\text { variable tenocyte density (usually } \\
\text { increased fibroblastic and } \\
\text { myofibroblastic cellularity); } \\
\text { evidence of microtears (fibrin, } \\
\text { hemosiderin) }\end{array}$ \\
\hline Paratendonitis* & $\begin{array}{l}\text { Inflammation of the } \\
\text { outer layer of the } \\
\text { tendon (paratendon) }\end{array}$ & Crepitus & Paratendinous edema & $\begin{array}{l}\text { Mucoid degeneration and } \\
\text { scattered inflammatory cells in } \\
\text { the paratendon }\end{array}$ \\
\hline $\begin{array}{l}\text { Paratendonitis with } \\
\text { tendinosis* }\end{array}$ & $\begin{array}{l}\text { Paratendonitis } \\
\text { associated with } \\
\text { intratendinous } \\
\text { degeneration }\end{array}$ & $\begin{array}{l}\text { Combinations of the } \\
\text { above }\end{array}$ & $\begin{array}{l}\text { Combinations of the } \\
\text { above }\end{array}$ & $\begin{array}{l}\text { Degenerative changes as noted } \\
\text { in tendinosis, with mucoid } \\
\text { degeneration, with or without } \\
\text { fibrosis, and scattered } \\
\text { inflammatory cells in the } \\
\text { paratendon }\end{array}$ \\
\hline Partial rupture & $\begin{array}{l}\text { Macroscopic defect } \\
\text { of collagen fascicles }\end{array}$ & $\begin{array}{l}\text { Tendon thickening; } \\
\text { pain on stretch; marked } \\
\text { weakness }\end{array}$ & $\begin{array}{l}\text { Collagen defect on } \\
\text { grey-scale } \\
\text { ultrasonography; } \\
\text { increased colour } \\
\text { Doppler signal, usually } \\
\text { on superficial surface }\end{array}$ & $\begin{array}{l}\text { Evidence of tearing, } \\
\text { inflammation and granulation } \\
\text { tissue; adjacent areas often show } \\
\text { tendinosis }\end{array}$ \\
\hline Complete rupture & $\begin{array}{l}\text { Complete loss of } \\
\text { continuity of tendon } \\
\text { fibres }\end{array}$ & $\begin{array}{l}\text { Lack of strength on } \\
\text { plantar flexion; Homan } \\
\text { sign }\end{array}$ & $\begin{array}{l}\text { Obvious defect on } \\
\text { ultrasonography }\end{array}$ & $\begin{array}{l}\text { Evidence of tearing, } \\
\text { inflammation and granulation } \\
\text { tissue; adjacent areas often show } \\
\text { tendinosis }\end{array}$ \\
\hline Insertional disorders & $\begin{array}{l}\text { Injury, inflammation } \\
\text { or degeneration of } \\
\text { the osteotendinous } \\
\text { junction, bursae or } \\
\text { both }\end{array}$ & $\begin{array}{l}\text { Tendon thickening and } \\
\text { tenderness on palpation } \\
\text { of the insertional area }\end{array}$ & $\begin{array}{l}\text { Hypoechoic areas or } \\
\text { defects adjacent to the } \\
\text { calcaneus; bursitis; } \\
\text { defects of the } \\
\text { calcaneus }\end{array}$ & Not available \\
\hline
\end{tabular}


dinitrate, is inconclusive. Corticosteroid injections should be avoided, and other injection therapies require more research before they can be recommended.

\section{Nonsteroidal anti-inflammatory drugs}

This review did not identify a randomized controlled trial of NSAIDs that met the inclusion criteria of symptoms lasting longer than three months. One trial of NSAIDs included some patients with chronic Achilles tendinopathy of less than six months' duration; that trial was rejected for inclusion during the initial literature search (Appendix 1, available at www.cmaj.ca/lookup/suppl/doi:10 $.1503 / \mathrm{cmaj} .101680 /$-/DC1) because it also included patients with acute Achilles tendinopathy. ${ }^{24}$ This trial found identical treatment outcomes in 70 patients randomly assigned to receive piroxicam or placebo tablets. The study is consistent with the clinical experience of one of us (K.K.) and with a lack of effect of NSAIDs in other types of tendinopathy. ${ }^{25}$

\section{Injection therapies}

A variety of injection therapies for the treatment of chronic Achilles tendinopathy has been examined in small clinical studies. These treatments include corticosteroids, sclerosing therapy, aprotinin, polidocanol, glycosaminoglycan polysulfate and platelet-rich plasma. ${ }^{26-32}$ Several studies

\section{Box 1: Summary of the literature review}

We performed an English-language literature review of randomized controlled trials of treatment for chronic Achilles tendinopathy. Appendix 2 (available at www.cmaj.ca/lookup/suppl/doi:10.1503/cmaj.101680/-/DC1) includes a complete description of our literature review. To be included, a study had to be a single- or double-blind randomized controlled trial of patients with chronic midportion Achilles tendinopathy. We included exercise trials that were single- as opposed to double-blind in design because exercise is a key component of management for chronic Achilles tendinopathy.

We searched Ovid MEDLINE (1950-August 2010) using a strategy combining terms related to Achilles tendinopathy with a search string for randomized controlled trials. In addition, we searched The Cochrane Library for systematic reviews of agents used for treating Achilles tendinopathy. The abstracts of identified studies were screened for relevance, relevant papers were reviewed independently by A.S. and E.H. and reference lists were further hand searched.

The methodologic quality of included studies was assessed independently by A.S. and E.H. using the Oxford scale, also known as the Jadad scale. ${ }^{13}$ We extracted data from the studies, calculated the Cohen's effect sizes (d) and tabulated the results.

Our search strategy identified 72 randomized trials of which 11 met the above inclusion criteria (Appendix 2). Included papers and their results are listed in Table $2 .{ }^{13-23}$

In the reviewed studies, a total of 777 patients were enrolled. The average age of the patients was 45.6 years, ranging from 18 to late 70 s. The ratio of male to female patients was not reported for all trials; the ratio in reported trials was 0.51 male to female. The duration of symptoms ranged from three months to several years. The most common outcome measures were pain at rest or with activity. have reported trends that are consistent with a clinically significant improvement, but are hampered by the small number of patients studied.

Fredberg and colleagues randomly assigned 24 patients with midportion Achilles tendinopathy to receive ultrasonography-guided corticosteroid (20 mg triamcinolone) or placebo injections. ${ }^{29}$ The authors commented that a significant number of patients treated with corticosteroid injection experienced initial improvements followed by a relapse of symptoms, but it is difficult to extract this information from the trial. An older study that included instances of both acute and chronic Achilles tendinopathy was not included in the current review, but we note here, in the absence of other available evidence, that these authors reported a lack of success with corticosteroid injection for the subset of patients with chronic Achilles tendinopathy. ${ }^{28}$

One randomized controlled trial examined the effect of injection of platelet-rich plasma on patients with Achilles tendinopathy; however, the study included patients with relatively acute conditions (two months' duration of symptoms) and thus did not meet our a priori inclusion criteria. ${ }^{33}$ Platelet-rich plasma is sometimes considered for instances of chronic, refractory tendinopathy, but there is as yet no evidence from randomized controlled trials to support or refute its use for chronic midportion Achilles tendinopathy. ${ }^{32}$

\section{Extracorporeal shock wave therapy}

The current evidence for shock wave therapy as a treatment for Achilles tendinopathy is inconclusive. Shock wave therapy involves the application of acoustic waves that vary in nature according to the type of device used and the amount of energy and energy flux delivered to the tissue. Because of the pain associated with active shock wave treatment, none of the available trials are adequately placebo-controlled. The evidence that met our criteria rests on two trials..$^{14,18}$

One trial examined the effect of adding lowenergy $\left(0.1 \mathrm{~mJ} / \mathrm{mm}^{2}\right)$ extracorporeal shock wave to a heavy-load eccentric exercise program. Patients who were randomly assigned to receive active shock waves plus exercise fared slightly better in terms of pain (1.5/10 improvement on a visual analogue scale; $p=0.0045$ ), activity level (13.5/100 improvement on the Victorian Institute of Sports Assessment-Achilles [VISA-A] score; $p=0.016$ ) and satisfaction with treatment at four months. ${ }^{18}$ Although statistically significant, these values may be clinically insignificant.

\section{Glyceryl trinitrate}

Two randomized controlled trials examined the effect of placing patches of glyceryl trinitrate 
directly over the painful Achilles midportion. Nitric oxide is essential to achieve normal healing of the tendon after acute injury; therefore, it may also be helpful in promoting repair of chronic injuries. ${ }^{34}$

Paoloni and colleagues randomly assigned 65 patients to receive rehabilitation (focusing on active tendon-loading exercises) plus glyceryl trinitrate for six months, or identical rehabilitation with placebo patches. ${ }^{23}$ The primary outcome measure was patient-rated tendon pain with activity. Four patients did not conclude the trial because of the development of headaches or skin rashes. In those who remained in the trial, there was a statistically and clinically significant decrease in pain with activity $(p=0.03)$. A second study by Kane and coauthors examined the effects of patches of glyceryl trinitrate and eccentric exercise versus placebo patches and eccentric exercise in 40 patients (20 per group). The main outcome measures were the Ankle Osteoarthritis Scale pain and disability scores. The scores of both groups were significantly decreased at six months, but the average scores were identical in the two groups. ${ }^{22}$ Thus, the initial promising results from Paoloni and colleagues' trial have not been supported by similar studies in other centres.

Table 2: Results of randomized controlled trials of treatment for chronic Achilles tendinopathy included in the review

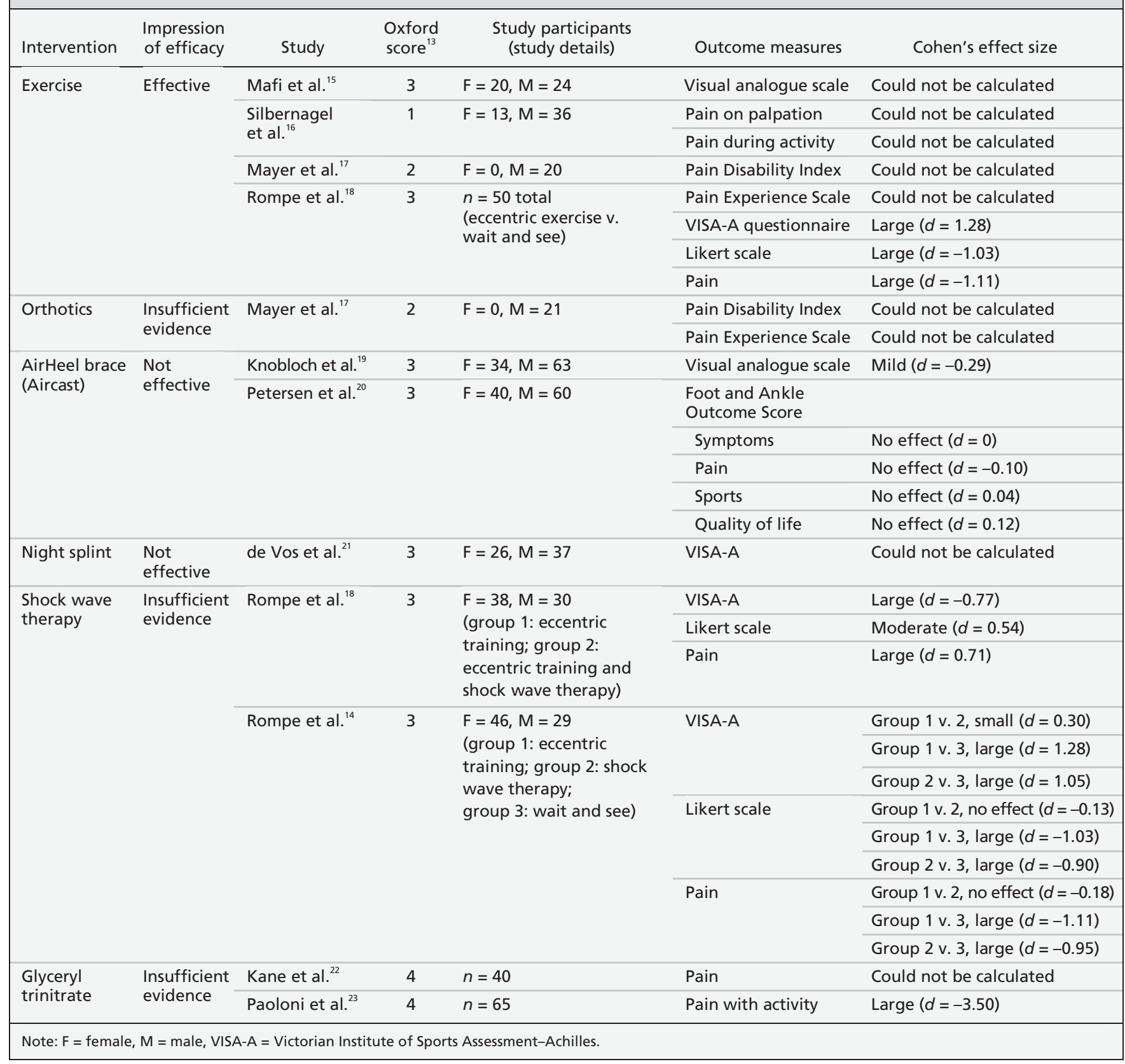




\section{What is the prognosis?}

Although tendinopathy may seem like relatively benign soft tissue pathology, recovery often follows a prolonged time course, even with ideal treatment. In one retrospective case series, $29 \%$ of patients who presented with symptoms of less than six months' duration were eventually referred for surgery. However, this series was published more than 10 years ago and may not reflect current successes with comprehensive rehabilitation. ${ }^{19}$ Because traditional surgical management has only a $50 \%$ rate of success, it is essential to ensure that the best conservative management has been offered before consideration of surgery..$^{20}$

The recalcitrant nature of chronic Achilles tendinopathy was documented by Rompe and colleagues, who noted that there was a slow but gradual improvement in the average loadinduced pain score from $7.9 / 10$ to $5.9 / 10$ over the course of four months in patients not receiving treatment. After this period, only $24 \%$ of

\section{Box 2: Applying the results of this review in clinical practice (fictional case)}

The role of the primary care physician is to establish the history and diagnosis, provide education on the chronic nature of the condition and the importance of rehabilitation, provide a referral to physiotherapy and monitor progress through rehabilitation (e.g., 6 or 8 weeks' follow-up).

A healthy 40-year-old woman presents with a four-month history of gradual onset of pain along her Achilles tendon, which has forced her to give up recreational running (her preferred form of exercise). She is $168 \mathrm{~cm}$ tall and usually runs $7-10 \mathrm{~km}$ per day, five days per week. There is no history of trauma or an obvious episode of strain or sprain. The pain is variable but is present throughout the day and also at night. It becomes severe with any attempt to start running again. Initially, the pain seemed to improve with ibuprofen, but now this gives no substantial benefit. There is no history of inflammatory disorder, diabetes or familial hypercholesterolemia. Physical examination shows a painful thickening in the midportion of the Achilles tendon, which triggers a sharp, localized pain when palpated. Radiography is normal. Ultrasonography shows thickening of the Achilles tendon with hypoechoic areas. What is the preferred treatment?

This patient requires education about the chronic, noninflammatory nature of the condition ${ }^{3}$ and the crucial role she will have to play in making rehabilitation successful. She would benefit from a

biomechanical assessment and a closely supervised exercise program with a graduated return to activity, both of which can be conducted by an appropriately experienced physical therapist. ${ }^{15,16}$

The use of a diary and the self-administered Victorian Institute of Sports Assessment-Achilles (VISA-A) scale ${ }^{36}$ may be useful in helping patients keep track of their exercise and their level of pain or function. ${ }^{16}$ The clinician could prescribe a glyceryl trinitrate patch ${ }^{23}$ or a course of lowenergy shock wave therapy in combination with exercise if there is no improvement after $4-8$ weeks, ${ }^{18}$ but these treatment options should be suggested with the caveat that the evidence for their efficacy is inconclusive. Exercise should be continued while these adjuvant therapies are trialed. If the condition remains unresponsive to treatment and the patient has substantial pain after six months, then further imaging and a surgical referral could be considered, preferably for a minimally invasive procedure. $^{35}$ these patients reported themselves as much improved or cured. ${ }^{14}$

In the long term, the prognosis of chronic Achilles tendinopathy is more favourable. At eight-year follow-up in one study of 83 patients, $80 \%$ of patients were back to full physical activities, whereas $20 \%$ reported that their physical activity was still impaired as a result of the Achilles tendinopathy. All patients could walk normally and had equal plantar flexion strength bilaterally, and $94 \%$ of patients could run normally. ${ }^{19}$

Box $2^{3,15,16,18,23,35,36}$ provides an example of the management of chronic Achilles tendinopathy, using the results of our literature review.

\section{Gaps in knowledge}

As summarized in Table 2, the evidence base for treatments other than exercise remains tenuous. Additionally, we do not know how different patient populations may respond to exercise. Clearly, young patients with active lifestyles may expect a better response to exercise than older patients with sedentary lifestyles, but response may be highly individualized. There is no magic formula for exercise prescription, and better data on prognostic factors would greatly assist clinicians in fine tuning their practice and advance our knowledge base.

Can exercise be used to prevent Achilles tendinopathy? Tendon does have an ability, like muscle or bone, to adapt to increased functional demand; however, this may not necessarily translate into an ability to prevent injuries. ${ }^{37}$ Will some of the pilot studies of ultrasonographyguided injection treatments be born out in larger randomized controlled trials? These are some of the many gaps in knowledge that we hope will be addressed in the coming years.

\section{References}

1. Brukner P, Khan KM. Clinical sports medicine. 2nd ed. Sydney (AU): McGraw-Hill; 2002.

2. Maffulli N, Wong J, Almekinders LC. Types and epidemiology of tendinopathy. Clin Sports Med 2003;22:675-92.

3. Khan KM, Cook JL, Bonar F, et al. Histopathology of common tendinopathies. Update and implications for clinical management. Sports Med 1999;27:393-408.

4. Clancy W. Tendon trauma and overuse injuries. In: Leadbetter W, Buckwalter J, Gordon S, editors. Sports-induced inflammation: clinical and basic science concepts. Park Ridge (IL): American Academy of Orthopaedic Surgeons; 1990. p. 609-17.

5. Khan KM, Cook JL, Kannus P, et al. Time to abandon the "tendinitis" myth. BMJ 2002;324:626-7.

6. Andersson G. Influences of paratendinous innervation and nonneuronal substance $P$ in tendinopathy: studies on human tendon tendon tissue and an experimental model of Achilles tendinopathy. Umea (SE): Umea University; 2010.

7. Backman C, Boquist L, Friden J, et al. Chronic achilles paratenonitis with tendinosis: an experimental model in the rabbit. J Orthop Res 1990;8:541-7.

8. Wren TA, Lindsey DP, Beaupre GS, et al. Effects of creep and cyclic loading on the mechanical properties and failure of human Achilles tendons. Ann Biomed Eng 2003;31:710-7. 
9. Warden SJ. Development and use of animal models to advance tendinopathy research. Front Biosci 2009;14:4588-97.

10. Gaida JE, Alfredson L, Kiss ZS, et al. Dyslipidemia in Achilles tendinopathy is characteristic of insulin resistance. Med Sci Sports Exerc 2009;41:1194-7.

11. Posthumus M, Collins M, Cook J, et al. Components of the transforming growth factor- $\beta$ family and the pathogenesis of human Achilles tendon pathology: a genetic association study. Rheumatology (Oxford) 2010;49:2090-7.

12. Maffulli N, Longo UG, Denaro V. Novel approaches for the management of tendinopathy. J Bone Joint Surg Am 2010;92 2604-13.

13. Jadad AR, Moore RA, Carroll D, et al. Assessing the quality of reports of randomized clinical trials: Is blinding necessary? Control Clin Trials 1996;17:1-12.

14. Rompe JD, Nafe B, Furia JP, et al. Eccentric loading, shockwave treatment, or a wait-and-see policy for tendinopathy of the main body of tendo Achillis: a randomized controlled trial. Am J Sports Med 2007;35:374-83.

15. Mafi N, Lorentzon R, Alfredson H. Superior short-term results with eccentric calf muscle training compared to concentric training in a randomized prospective multicenter study on patients with chronic Achilles tendinosis. Knee Surg Sports Traumatol Arthrosc 2001;9:42-7.

16. Silbernagel KG, Thomee R, Thomee P, et al. Eccentric overload training for patients with chronic Achilles tendon pain - a randomised controlled study with reliability testing of the evaluation methods. Scand J Med Sci Sports 2001;11:197-206.

17. Mayer F, Hirschmuller A, Muller S, et al. Effects of short-term treatment strategies over 4 weeks in Achilles tendinopathy. $\mathrm{Br}$ Sports Med 2007;41:e6.

18. Rompe JD, Furia J, Maffulli N. Eccentric loading versus eccentric loading plus shock-wave treatment for midportion achilles tendinopathy: a randomized controlled trial. Am J Sports Med 2009;37:463-70.

19. Knobloch K, Schreibmueller L, Longo UG, et al. Eccentric exercises for the management of tendinopathy of the main body of the Achilles tendon with or without the AirHeel Brace. A randomized controlled trial. A: effects on pain and microcirculation. Disabil Rehabil 2008;30:1685-91.

20. Petersen W, Welp R, Rosenbaum D. Chronic Achilles tendinopathy: a prospective randomized study comparing the therapeutic effect of eccentric training, the AirHeel brace, and a combination of both. Am J Sports Med 2007;35:1659-67.

21. de Vos RJ, Weir A, Visser RJ, et al. The additional value of a night splint to eccentric exercises in chronic midportion Achilles tendinopathy: a randomised controlled trial. Br J Sports Med 2007; $41: \mathrm{e} 5$

22. Kane TP, Ismail M, Calder JD. Topical glyceryl trinitrate and noninsertional Achilles tendinopathy: a clinical and cellular investigation. Am J Sports Med 2008;36:1160-3.

23. Paoloni JA, Appleyard RC, Nelson J, et al. Topical glyceryl trinitrate treatment of chronic noninsertional achilles tendinopathy. A randomized, double-blind, placebo-controlled trial. J Bone Joint Surg Am 2004;86-A:916-22.

24. Aström M, Westlin N. No effect of piroxicam on achilles tendinopathy. A randomized study of 70 patients. Acta Orthop Scand 1992;63:631-4.

25. Bisset L, Paungmali A, Vicenzino B, et al. A systematic review and meta-analysis of clinical trials on physical interventions for lateral epicondylalgia. BSMJ 2005;39:411-22.

26. Alfredson H, Ohberg L. Sclerosing injections to areas of neovascularisation reduce pain in chronic Achilles tendinopathy: a double-blind randomised controlled trial. Knee Surg Sports Traumatol Arthrosc 2005;13:338-44.

27. Brown R, Orchard J, Kinchington M, et al. Aprotinin in the management of Achilles tendinopathy: a randomised controlled trial. Br J Sports Med 2006;40:275-9.

28. DaCruz DJ, Geeson M, Allen MJ, et al. Achilles paratendonitis: an evaluation of steroid injection. Br J Sports Med 1988;22: 64-5

29. Fredberg U, Bolvig L, Pfeiffer-Jensen M, et al. Ultrasonography as a tool for diagnosis, guidance of local steroid injection and, together with pressure algometry, monitoring of the treatment of athletes with chronic jumper's knee and Achilles tendinitis: a randomized, double-blind, placebo-controlled study. Scand J Rheumatol 2004;33:94-101.

30. Shrier I, Matheson GO, Kohl HW III. Achilles tendonitis: Are corticosteroid injections useful or harmful? Clin J Sport Med 1996;6:245-50

31. Sundqvist H, Forsskahl B, Kvist M. A promising novel therapy for Achilles peritendinitis: double-blind comparison of glycosaminoglycan polysulfate and high-dose indomethacin. Int $J$ Sports Med 1987;8:298-303
32. Engebretsen L. IOC Consensus Statement on the use of plateletrich plasma $(P R P)$ in sports medicine. Lausanne $(\mathrm{CH})$ : International Olympic Committee; 2010.

33. de Vos RJ, Weir A, van Schie HT, et al. Platelet-rich plasma injection for chronic Achilles tendinopathy. JAMA 2010;303: 144-9.

34. Murrell GA, Szabo C, Hannafin JA, et al. Modulation of tendon healing by nitric oxide. Inflamm Res 1997;46:19-27.

35. Maffulli N, Longo U, Ramamurthy $\mathrm{C}$, et al. Minimally invasive stripping for chronic Achilles tendinopathy In: Maffuli N, Easley M, editors. Minimally invasive surgery of the foot and ankle. London (UK): Springer; 2011.

36. Robinson JM, Cook JL, Purdam C, et al. The VISA-A questionnaire: a valid and reliable index of the clinical severity of Achilles tendinopathy. Br J Sports Med 2001;35:335-41

37. Fredberg U, Bolvig L, Andersen NT. Prophylactic training in asymptomatic soccer players with ultrasonographic abnormalities in Achilles and patellar tendons: the Danish Super League Study. Am J Sports Med 2008;36:451-60.

Affiliations: From the Departments of Physical Therapy (Scott, Huisman) and Family Practice (Khan), University of British Columbia, Vancouver, BC

Contributors: Alex Scott conceived and drafted the article. Karim Khan contributed to the design and revision of the article. Elise Huisman acquired the data and revised the article. All authors approved the final version submitted for publication.

Acknowledgements: Alex Scott's research in tendon disorders is funded by Natural Sciences and Engineering Research Council of Canada, Canadian Institutes of Health Research and WorkSafeBC. Elise Huisman is the recipient of a WorkSafeBC PhD fellowship.

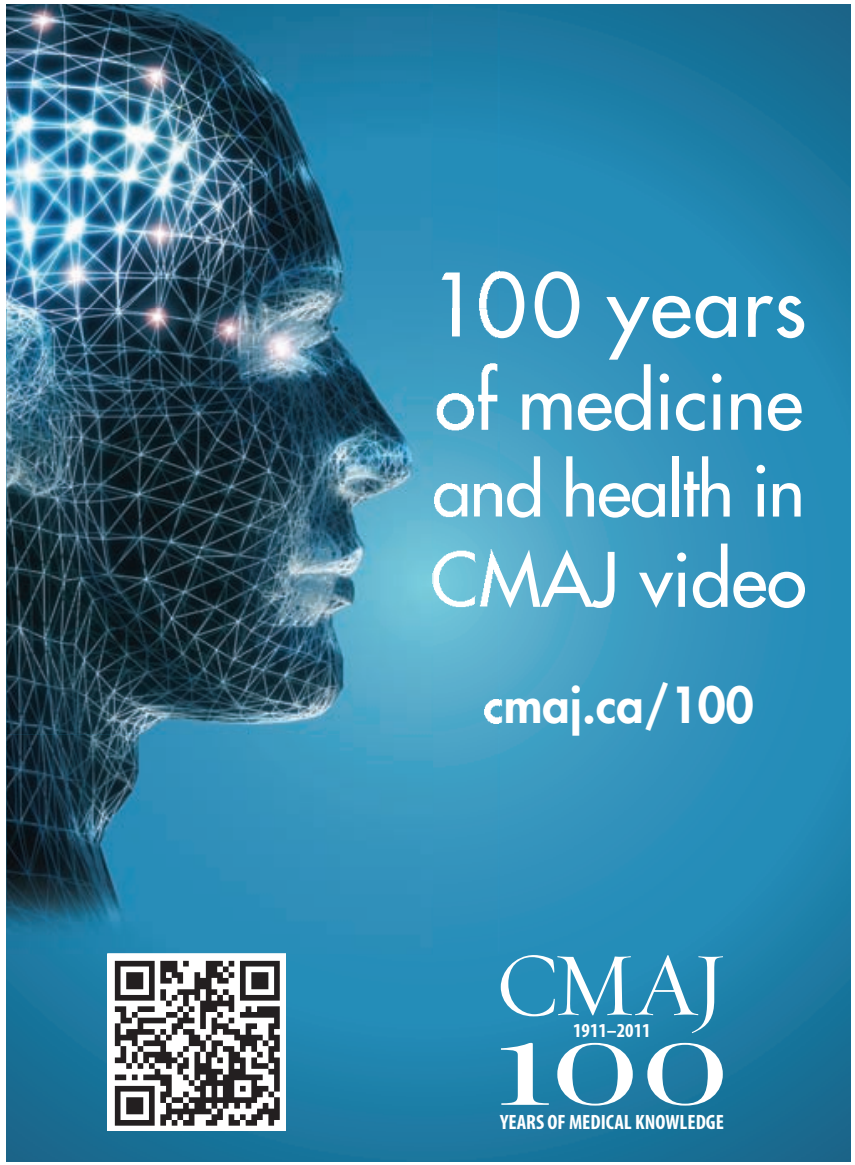

